\title{
Multicentric Castleman's Disease (CD) in juvenile idiopathic arthritis (JIA) treated with etanercept: coincidence or causal relationship?
}

\author{
L Rossi*, G Martini, L Sainati and F Zulian
}

Address: Department of Paediatrics, Padova, Italy

* Corresponding author

from $15^{\text {th }}$ Paediatric Rheumatology European Society (PreS) Congress

London, UK. 14-17 September 2008

Published: 15 September 2008

Pediatric Rheumatology 2008, 6(Suppl I):P56 doi:I0.I I86/I546-0096-6-SI-P56

This abstract is available from: http://www.ped-rheum.com/content/6/SI/P56

(C) 2008 Rossi et al; licensee BioMed Central Ltd.

Association of CD and RA is widely described in adults, but has never been reported in children with JIA. We report a 13 years old girl with a 6 years history of polyarticular JIA treated with Methotrexate (MTX) since diagnosis and after 2 years, in April 2004, started on etanercept. On this treatment, patient presented important clinical improvement which allowed steroids withdrawal and progressive reduction of MTX. In June 2007 recurrent attacks of migraine appeared with negative EEG and cerebral MRI. In November headache became continuous and after one month morning palpebral oedema and right chest pain appeared, followed by vomiting which lead to hospitalisation in January 2008. Noticeable elements on physical examination were: systolic hypertension, papilledema, palpebral and peripheral oedema, generalized lymphoadenopathy and hepatomegaly. Relevant lab tests were: $\mathrm{Hb} 11.6 \mathrm{~g} / \mathrm{dL}$, ESR $67 \mathrm{~mm} / \mathrm{h}$, CRP $21.6 \mathrm{mg} / \mathrm{L}$, hematuria, nephrotic proteinuria. Viral, bacterial and fungal infections were ruled out. Cerebral MRI showed right emisphere and right tentorial dural thickening (pachymeningitis). CT and ultrasound confirmed the presence of enlarged mediastinal and axillary lymph nodes, pericardial and pleural effusion, bilateral renal enlargement and ascites. Plasmocytosis was found on bone marrow aspirate. Axillary lymph node biopsy was consistent with CD.

To our knowledge this the first report of the combination of two conditions rarely associated with RA, multicentric CD and pachymenigitis, in a child with JIA in remission under treatment with etanercept. This raises the question whether anti TNF- $\alpha$ therapy might contribute to lymphoproliferation possibly via dysregulation of cytokines network

\section{References}

I. Waterson A, Bower M: Fifty years of multicentric Castleman's disease. Acta Oncol 2004, 43(8):698-704. 